\title{
SPANISH SOCIAL HOUSING IN THE 20TH CENTURY: TYPOLOGICAL ANALYSIS OF RESIDENTIAL COMPLEXES BUILT IN CASTELLÓN IN THE 1950S
}

\author{
MANUEL CABEZA GONZÁLEZ, BEATRIZ SÁEZ RIQUELME, MARÍA JOSÉ RUÁ AGUILAR, \\ PATRICIA HUEDO DORDÁ \& RAQUEL AGOST FELIP \\ Jaume I University, Spain
}

\begin{abstract}
Since the 1940s, populations of Spanish cities have grown intensely, which was motivated mainly by rural emigration. In order to provide housing for such population growth, a great deal of social housing was built. The state would initially and directly control the implementation of this new urban structure by establishing a relative unitary housing typology, especially in the 1950s when most social housing legislation was introduced. These buildings, which helped shape the outskirts of cities at the time, now form part of their consolidated urban pattern, and their image shows the social character that identified these building types. At the same time, both the building image and housing typology are an anachronistic reference that needs to be intervened in order to adapt to changing life habits that today's society demands. In Castellón, most of these social housing were carried out in the 1950s by the Obra Sindical del Hogar, an organisation that depended on the Instituto Nacional de la Vivienda, and was responsible for most of the social housing built during this period. This paper shows the results of the typological analysis of these residential complexes, which seems to indicate the obsolescence of such a housing type and, at the same time, offers valuable information to refurbish this large building stock in the city according to new users' needs.
\end{abstract}

Keywords: housing typology, Castellón de la Plana, Obra Sindical del Hogar.

\section{INTRODUCTION}

At the end of the Civil War, Spanish cities began to experience an important growth of their populations mainly motivated by the massive arrival of peasants which wanted to find the necessary work to be able to live.

This significant influx of new workers together with the necessary recovery of the urban centres which had been severely punished during the years of the conflict, forced the official agencies to urgently address the reconstruction of the cities, with particular attention to the necessary accommodation for the new working classes newly arrived from the countryside.

In order to carry out the different tasks, some official bodies were created. Thus, the Dirección General de Regiones Devastadas, launched in January 1938 [1], dealt with the reconstruction of urban centres which were damaged during the war. A year later, in April 1939, the Instituto Nacional de la Vivienda [2] was created and its primary responsibility would be to implement the first Law on Protection to Low-Income Housing System for the most humble classes.

This law repealed the previous legislation and the State was stood by as solely responsible for the construction of this type of housing. In this way, private initiative was practically excluded from this activity and the State, through the official bodies created for this purpose, maintained a comprehensive control of these constructions.

The Instituto Nacional de la Vivienda was responsible for managing the construction of the necessary housing plans, most of which were commissioned to the Obra Sindical del Hogar y Arquitectura, technical organization created in December 1939 and subordinate to the Organización Sindical Española as well as the Ministerio del Interior. However, the work of this body would not be noticeable until the following decade from the publication in 1954 
of the social housing plan [3] and the express assignment to build annually 20,000 dwellings for workers. all over the national territory [4]. These regulations on social housing would be supplemented by the adoption in the same year of the Law on Protection to Limited Income Housing [5].

All this legislation aim the promotion and protection of housing for the working class, regulating the minimum surface dimensions that this type of housing should have, as well as the constructive and economic aspects with which to guarantee their production.

For more than 60 years, these dwellings have served as lodgings for the most humble classes of the city's population where they were built, thus demonstrating the value of the models used at the time by the Obra Sindical del Hogar. However, both the passage of time and the normative evolution in the field of housing make it necessary to intervene in these housing buildings to adapt them to current needs. So, it is necessary to make a thorough study of these models to be able to draw up the corresponding proposals for intervention.

This is the main objective of the research project in which this work as the first phase and it consist in a typological study of these models built during this period of time in Castellón de la Plana.

\section{METHODOLOGY}

The work has been developed following a series of phases. First of all, the study cases were selected. They had to be significant samples of this housing type and should collect the maximum variety.

This selection has been carried out from the information of the Municipal Historical Archive of the city, where the architectural projects of the protected dwellings groups are preserved. Those carried out by Obra Sindical del Hogar during the 1950s were extracted and a significant sample was selected from among them.

It was carried out a comprehensive analysis from each group of dwellings, focusing in three points of view: urban site, residential grouping and, finally, typologies of dwellings. This analysis and its subsequent comparison with the current regulatory will serve to highlight the gaps and needs of the analysed models, which will be a starting point for drawing up the optimal intervention proposals for each case and which can be used as a reference for future actions in this type of housing.

\section{RESULTS}

The three selected housing groups are signifying examples of the Obra Sindical del Hogar's production carried out in Castellón de la Plana during the 1950s. They collect the architectural criteria which regulated the building of this type of houses in those years. In particular, those relating to the Law on Protection to Low-Income Housing System published in July 1954 and the 20,000 workers' housing annual plan for regulated by the Decree-Law of 29 May in the same year.

\subsection{Housing groups}

Group 1. Nuestra Señora de los Ángeles (1955-1957)

Site: Magallanes, Gravina and Sebastián Elcano Streets in Grao de Castellón Houses number: 56

Plot area: $1,916 \mathrm{~m}^{2}$

Occupied area: $756 \mathrm{~m}^{2}$

Architect: Vicente Vives Llorca 
This is one of the interventions that the OSH carried out within the 20,000 workers' housing Annual Plan. They were built as minimum income houses type $B$ and type $C$, with constructed surfaces less than 50 and $42 \mathrm{~m}^{2}$ respectively.

Group 2. San Vicente Ferrer (1958-1960)

Site: West Park, Pintor Camarón Street and Hermanos Quintero Street

Houses number: 80

Plot area: $2,204 \mathrm{~m}^{2}$

Occupied area: $1,075 \mathrm{~m}^{2}$

Architect: Vicente Vives Llorca

This intervention was carried out following the Law on Protection to Low-Income Housing System, with typologies within the third category, the most economical, whose built surfaces could be up to $92 \mathrm{~m}^{2}$.

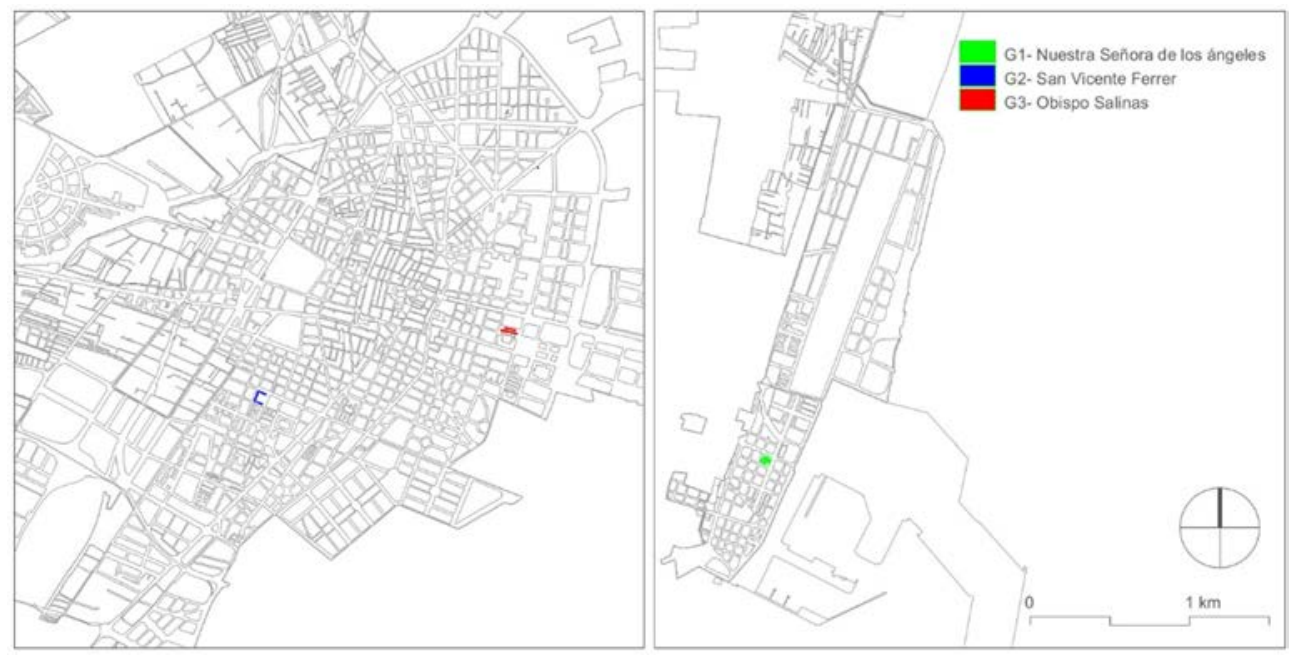

Figure 1: Catellón de la Plana and Grao Plan with housing groups location. (Source: Own elaboration.)

Group 3. Obispo Salinas (1958-1960)

Site: Obispo Salinas Street

Houses number: 80

Plot area: $3,369 \mathrm{~m}^{2}$

Occupied area: $1,436 \mathrm{~m}^{2}$

Architect: Vicente Vives Llorca

This third group of housing, like the previous one, was carried out following the Law on Protection to Low-Income Housing System, with typologies within the second and third categories, whose surfaces were not to exceed 150 and $92 \mathrm{~m}^{2}$ respectively. 


\subsection{Urbanisation}

The three interventions were located in the city growth zone. Each of them partially occupied one of the planned blocks.

The size of these blocks allowed to introduce the functional criteria for low cost rational housing which 25 years earlier had been established at the CIAM in Frankfurt [6]. Thus, in the three residential housing groups we find narrow linear buildings that ensure a cross ventilation and avoids the use of inner courtyards, since every dwellings have, at least two façades. The result contrasts with an urban surrounding where the blocks are filled with building.

In the two groups located in the capital, the linear buildings delimit the perimeter of the block and the inside is occupied by other residential buildings, in one of the cases with the same type of building and in the other with a residential tower. Only in the case of the group located in Grao, the whole plot is occupied by linear buildings, arranged in parallel throughout the width of the block.

Consistent with this building rationality and its link with the functionalism of the first modern architecture, the inner spaces between buildings are equipped with inner streets and a large number of parking.

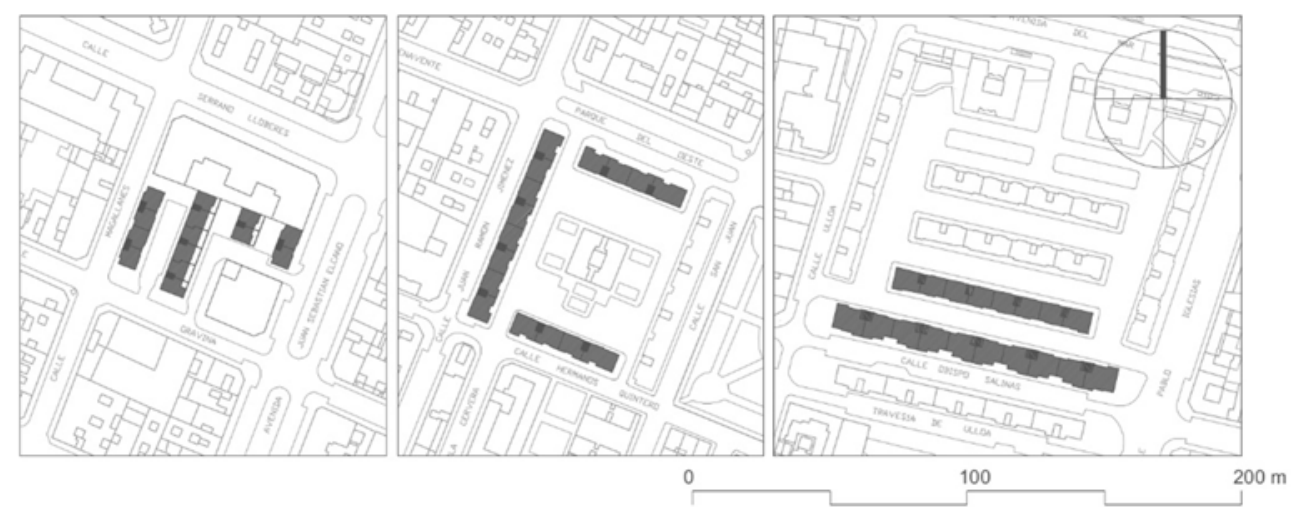

Figure 2: Site Plans. Group 1, Group 2 and Group 3. (Source: Own elaboration.)

This priority of the road traffic over the pedestrian shows a delay with respect to the proposals, in those years, were being applied in other capitals such as Madrid or Barcelona where, following the Nordic influences, react against the excessive schematic of rationalist architecture, incorporating psychological factors in its approaches and returning man and his habits to the centre of the question [7]. As a result, housing was not only economically and functionally optimized but also surrounded by a pleasant environment that enhanced community life.

\subsection{Residential grouping}

The way of grouping dwellings is the same in the three groups and it is a consequence of the double façade of the dwellings that forces to have a vertical communication core every two dwellings. In this way, the linear buildings adapt to plot length adding more or less of these vertical communication cores. 
Among nine linear buildings comprising the three housing groups analysed, seven use a stairway in two sections facing perpendicular to the façades, one more uses a stairway in one section following longitudinal direction and the last one is solved with a stairway in three sections. Among the three stairway typologies, the first allows to access deeper to the dwellings inner, which makes easier the house distribution and decreases the circulations areas within the dwellings.
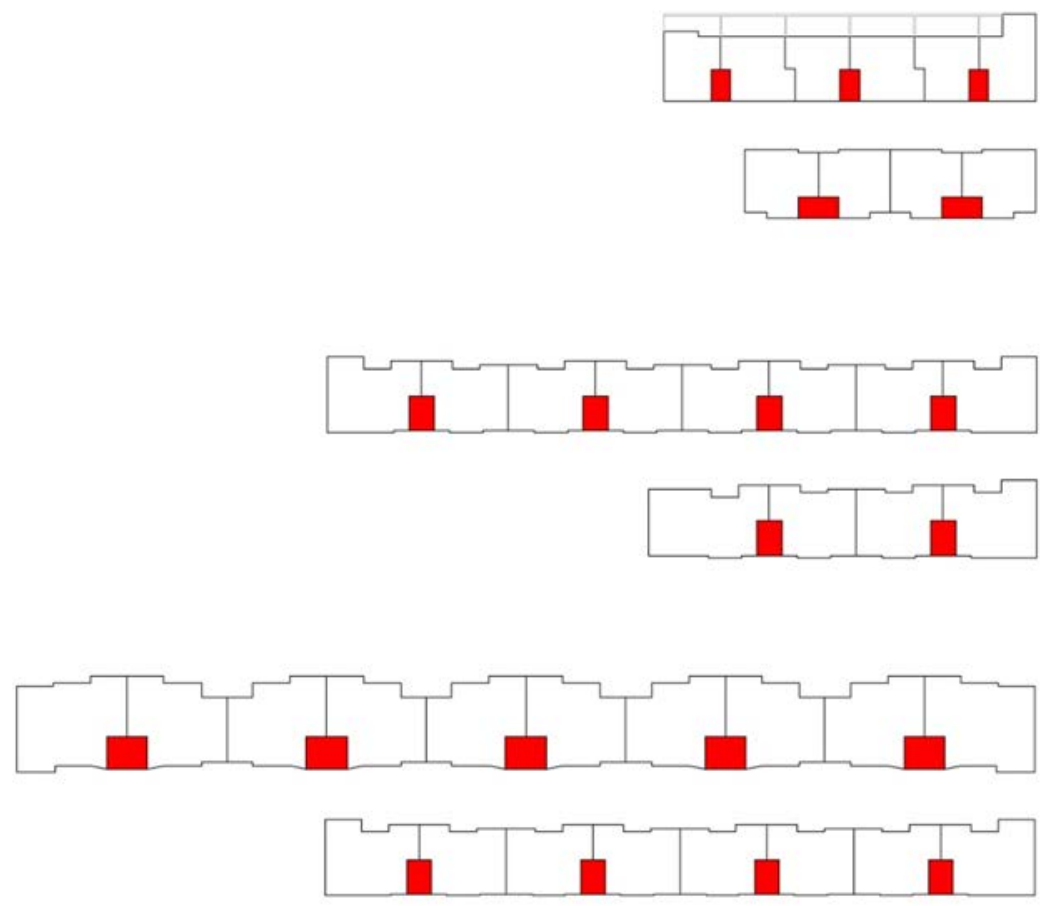

0

Figure 3: Residential grouping. (Source: Own elaboration.)

Except two cases, the supporting structure is arranged in perpendicular to the façade line which is reflected on the outside with continuous retractions throughout the length of the linear building and it is a consequence of the area each room needs.

Only two of the linear buildings in the Grao group use another type of supporting structure. In this case, it is solved with walls run alongside the building, which generate two bays of constant depth throughout the length of the building. In this way, continuous elevations are achieved only interrupted at the ends that move slightly outwards to increase the occupied area. This is achieved by the interruption of one of the bays which is replaced by a new bay in perpendicular direction.

Regarding to integrated uses in buildings, in all cases housing is the only use included at every floors, including on the ground floor, according to the residential character of the complex. In addition, all the linear buildings are covered with a flat roof. 


\subsection{Housing unit}

As it has been said above, thanks to the narrow linear buildings a cross ventilation is possible in every dwelling. This type of dwelling is rooted in the hygienist principles of rational architecture from the beginning of the twenty century which required to ensure a right lighting and ventilation of each of the rooms that had to be done directly through outdoor areas.

Functionally, three types of housing are distinguished:

Type 1. This type is the most used. Every dwelling in the second group used it, as well as 24 of the first and half of the third group. In total, 144 dwellings, this is two thirds of the built dwellings in the three groups.
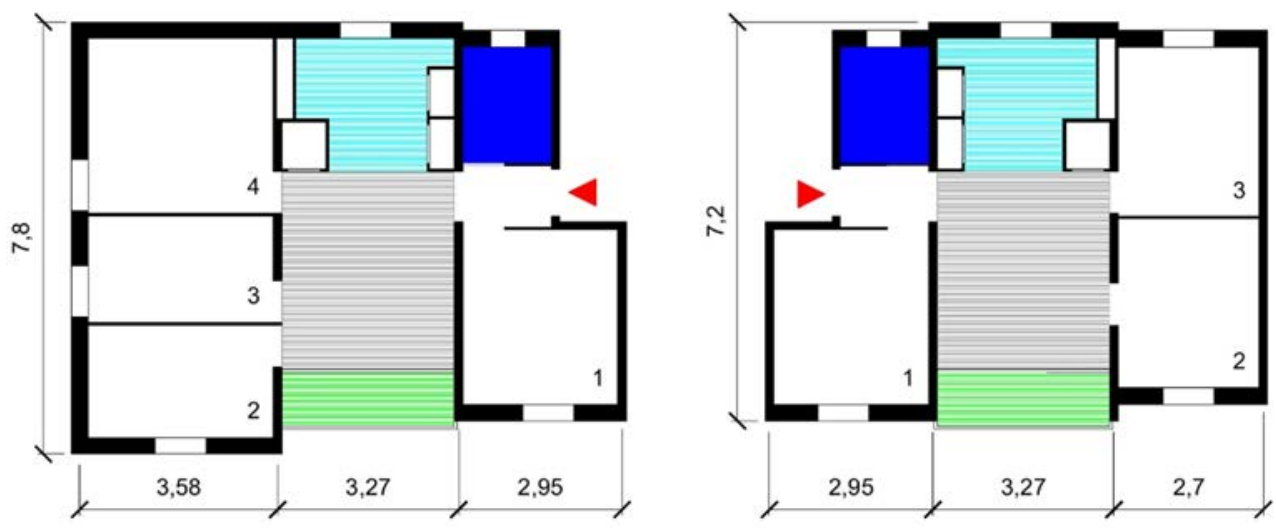

Figure 4: Type 1 and option. Floor plan. (Source: Own elaboration.)

In this type of dwelling, the supporting structure is arranged perpendicular to the façade to create different size bays with a maximum depth of $7.2 \mathrm{~m}$ which allows to house two rooms per bay, thus, each room is light up from an opposite façades.

In this way, the first bay is composed by the bathroom and the master bedroom which are separated by a small entrance foyer. The staircase also is a part of this first bay. The central bay contains whole program of day area, kitchen and living-dining room meanwhile the third and last one is completed with two other bedrooms.

One variation on this type is used in the first group where the rooms of the first and second bays are different. Thus, the first bay consists of wet areas, kitchen and bathroom, on one side and the staircase on the other, meanwhile the central bay is occupied by the living room and the master bedroom.

Dwellings are arranged symmetrically respect to staircase and all of them have three bedroom, except at the ends of the building where dwellings have four and five bedrooms. At one end, the last bay is extended to increase its area to be occupied by three bedrooms instead of two. At the other end, it is added a new bay with two bedrooms.

Type 2. This type is used in half of the dwellings in group 3.

As in the previous type the supporting structure is arranged perpendicular to the façade although this time the building is solved with three bays with different widths and a depth 
which exceeds $9 \mathrm{~m}$. This larger size is used to get a larger area of each of the rooms, so a larger dwelling with more than $20 \mathrm{~m}^{2}$ than those of the previous type.

Unlike the previous ones, this type of housing does not use the living room as a foyer, but it is placed on the first bay where the staircase and entrance foyer are too. Rest of the rooms are accessed from an interior corridor. The dwellings incorporate a gallery that, although it is in communication with the kitchen, it occupies the same bay that the living room. Wet areas, bathroom and kitchen, are placed in the middle bay, which they share with the master bedroom, remaining the rest of the bedrooms in the last bay.

As type 1, dwellings are arranged symmetrically respect to staircase and all of them have three bedroom, except at the ends of the building where dwellings have four bedrooms thanks to the increase of the area of the last bay where three bedrooms are placed.
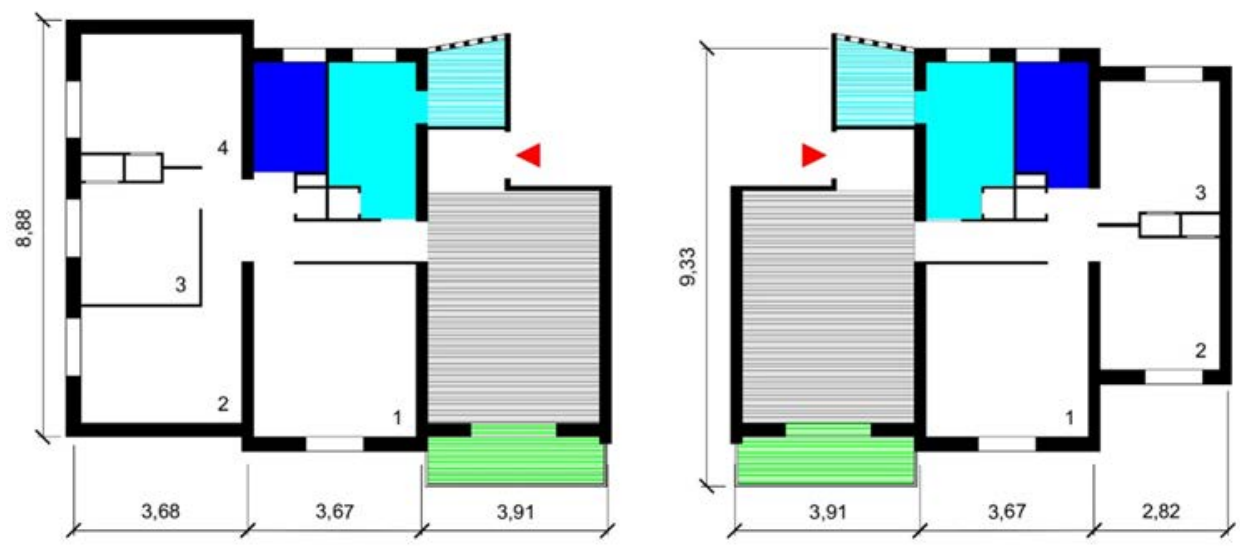

Figure 5: Type 2 and option. Floor plan. (Source: Own elaboration.)
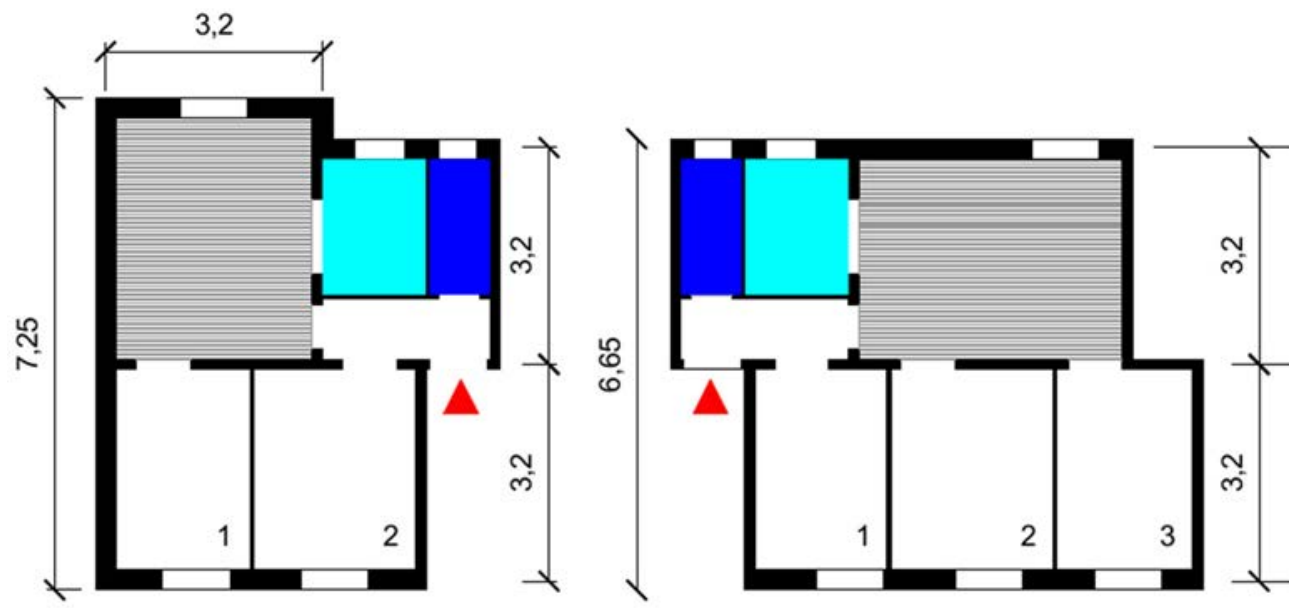

Figure 6: Type 3 and option. Floor plan. (Source: Own elaboration.) 
Type 3. This type was only used in 32 dwelling of the group 1 .

In this type, the supporting structure configures two bays with constant width alongside the building so the depth of the dwelling is determined by the width of these two bays. This is a bit more than $6.5 \mathrm{~m}$, the smallest of all the cases studied.

Another difference is how the dwelling are placed that in this case they are not symmetrically arranged respect to staircase, but dwelling with two and three bedrooms are alternating alongside the building.

Two variations on this type were projected at the ends of the building. They are consequence of partially increasing the depth of the day area thanks to the addition of a new perpendicular bay. This increases of the area is occupied by the living room at one end and by a bedroom in the other.

The housing programme is distributed in such a way that the whole day area is included in the east facing bay while the night one falls on the opposite to west. The living room also works here as a foyer, minimizing the circulation areas which are reduced to the small entrance area.

\section{CONCLUSIONS}

The analysis carried out shows the appropriateness of rationalist models for massive production of this type of low-income housing, in particular during the years of economic shortage suffered by Spanish cities like Castellón in the middle of the last century.

In Castellón, this lack of resources was possibly the main cause of the delay in the implementation of the new trends coming from northern Europe which were already being applied in other parts of the country where proposals were focused on the human aspect of common outdoor spaces to create environments with a scale closer to the individual, instead the functionality of the rationalist linear building.

This priority of the economy can be seen not only in the minimal sizes of the dwelling but in the adoption of the most profitable constructional systems like the bearing walls in perpendicular direction to the façade line which allows the easy expansion of the area to be constructed in each bay, according to the needs of the rooms.

As a counterpart, this structural system entails no discrimination of orientations between the day area and the night area, the bedrooms are placed in both orientations, which is a new evidence of the preference for structural system over the functional arrangement.

Another of the characteristics that emphasizes the economical character of these housing buildings is the reduction of the circulation areas to the minimum, as it is shown by the central position of the living room that acquires, in most of the housing, the function of foyer to access the rest of the rooms.

From a urban point of view, these interventions were intended only as housing containers, as evidenced by the absence of shops on the ground floors. This has caused the appearance of residential areas in the city which, depending on the size of the intervention, have become a neighbourhood.

\section{ACKNOWLEDGEMENTS}

The research for this work was carried out in the framework of the Project GV/2017/110, Diagnosis and proposals for the regeneration of public housing buildings for social inclusion purposes (VIVINSO), within the Research, Development and Innovation projects developed by emerging research groups GV-2017, funded by the Valencia Autonomous Government. 


\section{REFERENCES}

[1] Law of 31 December 1938 organizing the Central State Administration, with the creation, among others, of the Dirección General de Regiones Devastadas in Official State Gazette 467, 31 January 1938.

[2] Law of 19 April 1939 on Protection for Low-Income Housing System and establishing the Instituto Nacional de la Vivienda in Official State Gazette 110, 20 April 1939.

[3] Decree-Law of 14 May 1954 entrusting the Instituto Nacional de la Vivienda a Social Housing Plan in Official State Gazette 168, 17 June 1954.

[4] Decree-Law of 29 May 1954 entrusting the Obra Sindical del Hogar, in collaboration with the Instituto Nacional de la Vivienda, to build twenty thousand annual dwelling for producers of the Organización Sindical in Official State Gazette 168, 17 June 1954.

[5] Law of 15 July 1954 on the Protection of Limited-Income Housing in Official State Gazette 197, 16 July 1954.

[6] Pérez Igualada, J., Si cambia la vivienda cambia la ciudad. La vivienda pequeña y sus formas de agrupación en la Valencia de Posguerra. Renta Limitada. Los grupos de viviendas baratas construidos en la Valencia de posguerra (1939-1964). Editorial de la UPV: Valencia, pp. 40-48, 2008.

[7] Richards, J.M., Pevsner, N., Lancaster, O. \& Hasting, H. de C., The new empiricism. The Architectural Review, 606, pp. 199-204, 1947. 